\title{
PLANNING AND SUSTAINABLE DEVELOPMENT OF URBAN LOGISTICS: FROM INTERNATIONAL GOALS TO REGIONAL REALIZATION
}

\author{
FRANCESCO RUSSO \& DOMENICA SAVIA PELLICANÒ \\ Dipartimento di ingegneria dell'Informazione, delle Infrastrutture e dell'Energia Sostenibile, \\ Università degli studi Mediterranea di Reggio Calabria, Italy
}

\begin{abstract}
Urban transport has negative impacts on sustainability development in environmental, economic and social terms. The freight flows must be organized in such a way as to achieve sustainable development objectives through measures generating benefits and reducing costs on different levels of the supply chain. To promote sustainable urban logistics it is necessary to analyze the city development collecting the main data on the stakeholders behavior and planning actions for virtuous behavior to provide the best practices. The paper will focus on the rules about city logistics, considering the framework of the international and national goals to identify the way of transmission from one level to another. The rules processed at different territorial levels will show the absence of a well-defined link between one level and another and the voluntary choice of each administrative level to agree, or not, to the sustainable development process. The case of Calabria will be described. Calabria, achieving goals derived from the UN, the EU and by the Italian State, through planning tools, such as the Regional Transportation Plan (RTP) and the Economy and Finance Document of Calabria Region 2019-2021 (EFD), is an exemplary case of best practices. It is promoting and driving city logistics rules for implementation of sustainable development.
\end{abstract}

Keywords: Agenda 2030, sustainable development, planning, urban transport, green city logistics.

\section{INTRODUCTION}

The urban freight transport has acquired, in the last decades, growing importance. It is an essential service for citizens; its main component is the supply of commercial activities but just-in-time services, home deliveries and e-shopping play an important role.

This has led to an ever-increasing number of deliveries and freight vehicles in residential areas, generating heavy impacts on city sustainability and liveability [1]-[3].

Freight transport involves air and noise pollution, congestion, energy consumption, deterioration of architecture, safety problems, etc. It contributes to non-sustainable effects on [4], [5]:

- the environment (congestion, air pollution, noises issues [6]-[8]);

- the economy (changes in logistic costs [9]-[13]); and

- society (an increasing risk of accidents due to a combination of different types of vehicles on the road [14], [15]).

The economic development of a territory can thus be compromise by the markets evolutions if it is not related to an efficient and effective logistics, both in terms of a coordinated set of services and as infrastructural networks.

A framework of knowledge should be made available to public and private decision makers to operate efficiently and effectively in urban traffic, trying to resolve the conflict between the objective of improving the quality of the city environment and the objective to maintain its economic and social vitality.

The problem is complex because the urban freight flows must be organised without negative impacts on the efficiency and effectiveness of supply chain; urban logistics is only 
the last link of a large process involving a lot of stakeholders. Intervening on the last ring means modifying the remaining chain and vice versa; the choices of the subjects that are upstream (wholesale suppliers, producers and distributors) cannot be ignored, just as the choices of the downstream subjects (retailers and consumers) cannot be ignored.

It is necessary that all the actors of the supply chains are empowered of the consequences on the community deriving from their economic choices; the problem must be addressed in an integrated and rational way. Sustainable development objectives can be achieved by measures that are sometimes conflicting and generate impacts that depend on the acceptance of stakeholders as well as external factors [16].

To better present the phenomenon of the freight urban transport, three interconnected processes can be identified schematically: city development, city planning theories and city policy and rules [17] (Fig. 1). The analysis of the three processes is important so that planners and city decision makers can operate in a coherent way, with - from one way - the real development of the city and individual decision of retailer and users and - from another way - with the urban and transportation theories developed in the research centres by the observation of real phenomena.

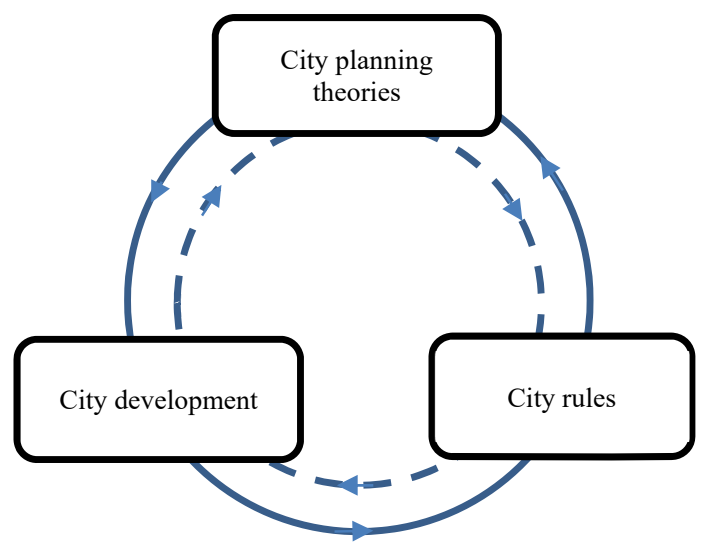

Figure 1: Circular ways among the processes [17].

Uncontrolled urban growth has made the cities as a mega-systems consisting of complex heterogeneous and autonomous systems. The city should be consistent with the size of the built infrastructure, service functions and activities.

The analysis of real city logistics development allows researchers to investigate and provide general guidance for identifying best practices. The collected data give detailed information on the stakeholders behavior and identify/plan actions for virtuous behavior.

The study of city development leads thus to the theory that is the planning. Urban planning theories "were the application of a scientific method to decision-making" [18]; "planning is a form of system analysis and control" [19].

Systems have dynamic characteristics whereby plans do not have to be seen as static documents, but rather as dynamic and changeable as the systems themselves.

The planning process identifies three phases: objectives formulation, identification and definition [20]. 
Theories can help city planners or city administrators in planning, for example to identify the set of best performing sustainable measures based on some characteristics of the city where a plan needs to be implemented [21], [22].

City rules, leaving from plan, allows to define some city rules as guidelines and laws, at different territorial levels, to regularize and govern the development of the city. Rules are generally linked to the context to which they are applied but, at the same time, there are common cultural values on the quality of life that allowing to the convergence of the city rules [23].

In recent years, the European Union (EU) has attempted to introduce common standards on cities in spatial planning [24].

Paper focuses on city rules and aims to address the topic of city logistics to understand how rules are developed at different administrative levels and how the rules of the highest level can be transmitted and received at the lowest level and vice versa (Fig. 2).

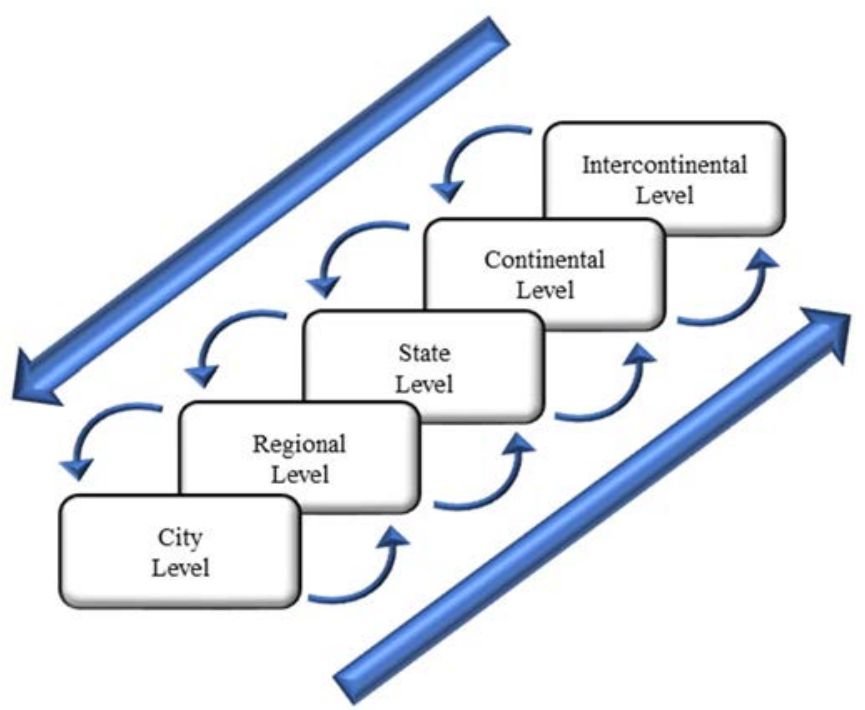

Figure 2: City level processes.

The paper acts as a support to understand how the process of transmitting and transposing rules from one level to another develops in a dynamic way. Each level can contribute to all the other levels also skipping levels of direct interconnection using the practice of consultation. In which a higher level as Europe can discuss directly with the cities skipping national and regional levels.

It's evident that for each territorial level a circular process, as the one recalled in Fig. 1 for the city, can be proposed.

Paper provides a careful analysis of the sustainability objectives finalized to city logistics decided on different territorial levels: International, European, National and Regional scale. Specifically, UN, EU, Italy, Calabria are considered.

\section{SUSTAINABLE DEVELOPMENT GOALS}

The first definition of sustainable development was coined in 1987 in the "Our Common Future" report, better known as the Brundtland Report [25]. 
Sustainable development is "development that meets the needs of the present without compromising the ability of future generations to meet their own needs". It contains within it two key concepts:

- the concept of "needs", in particular the essential needs of the world's poor, to which overriding priority should be given; and

- the idea of limitations imposed by the state of technology and social organization on the environment's ability to meet present and future needs.

Development involves a progressive transformation of economy and society. A development path that is sustainable in a physical sense could theoretically be pursued even in a rigid social and political setting. But physical sustainability cannot be secured unless development policies pay attention to such considerations as changes in access to resources and in the distribution of costs and benefits. Even the narrow notion of physical sustainability implies a concern for social equity between generations, a concern that must logically be extended to equity within each generation [25].

This leads to affirm that sustainability is characterized by three fundamental components:

- economic sustainability as the ability to generate income and work for the population livelihood;

- social sustainability as the ability to guarantee conditions of human well-being (safety, health, education, democracy, participation, justice) equally distributed by classes and gender;

- environmental sustainability as the ability to maintain the quality and reproducibility of natural resources.

Development cannot subsist upon a deteriorating environmental resource base; the environment cannot be protected when growth leaves out of account the costs of environmental destruction. These problems cannot be treated separately by fragmented institutions and policies. They are linked in a complex system of cause and effect.

No single blueprint of sustainability will be found, as economic and social systems and ecological conditions differ widely among countries [25].

\subsection{UN goals}

At international level, the path of sustainable development was launched in the 1972 with Stockholm Conference on the Human Environment, in which it was proclaimed that: "the protection and improvement of the human environment is a major issue which affects the well-being of peoples and economic development throughout the world; it is the urgent desire of the peoples of the whole world and the duty of all Governments".

After, there were numerous international meetings to discuss sustainable development. Some ones are mentioned below.

In the 1980s the International Union for Conservation of Nature (IUCN) published the World Conservation Strategy [26] that "provides both an intellectual framework and practical guidance for the conservation actions necessary...". It is to help advance the achievement of sustainable development through the conservation of living resources. The Strategy:

1. explains the contribution of living resource conservation to human survival and to sustainable development;

2. identifies the priority conservation issues and the main requirements for dealing with them; and 
3. proposes effective ways for achieving the Strategy's aim.

In 1987 the "World Commission on Development and Environment" was established to elaborated the Brundtland Report giving the first definition of sustainable development as already mentioned above [25].

In 1992, in Rio de Janeiro, the UN Conference on Environment and Development was held, in which the contents of the 1972 Stockholm UN Conference Declaration were confirmed. This Conference has triggered two important initiatives:

- Agenda 21: Programme for actions for Sustainable Development, it constitutes a manual for the sustainable development of the planet from here to the 21st century [27].

- United Nations Framework Convention on Climate Change [28], underwritten in New York on 9 May 1992. It is the first legal tool on climate change, with the aim of stabilizing the atmospheric concentrations of greenhouse gases deriving from human activities, in order to prevent dangerous effects. The implementation tool of the Convention was the Kyoto Protocol, signed in 1997.

Kyoto Protocol [29] was drafted by 169 nations to reduce, for the 2008-2012 period, the total greenhouse gas emissions by at least $5 \%$ compared to 1990 levels (taken as the reference year), in order to remedy the ongoing climate changes. To achieve the set objectives, the actions must be aimed in particular at:

- replace non-renewable energy sources with renewable energy sources;

- reduce the fossil fuels use;

- increase energy efficiency;

- reduce energy consumption; and

- reduce deforestation.

Other important meetings were held at Johannesburg (2002), Durban South Africa (2011), Rio de Janeiro (2012), etc.

In September 2015, 193 UN member states approved the document "Transforming our World: The 2030 Global Agenda for Sustainable Development" [30]. It encompasses 17 sustainable development goals (SDGs) in a major program of action for a total of 169 targets with 244 indicators. The goals are shown in Fig. 3.

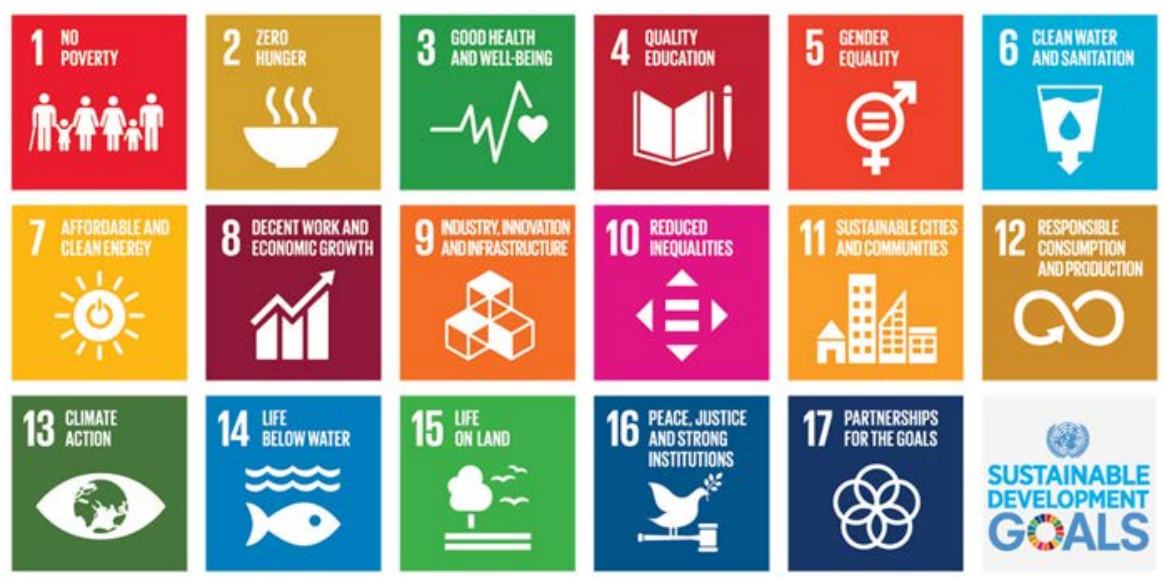

Figure 3: Sustainable development goals [30]. 
Each goal is made up of one to three indicators that are used to measure progress towards the full achievement of the same, for a total of 244 indicators which are reported in the global indicator framework for the sustainable development goals and targets of the 2030 Agenda for Sustainable Development [31].

In relation to city logistics the considered goal is 11: Make cities and human settlements inclusive, safe, resilient and sustainable.

The target is 11.6: By 2030, reduce the adverse per capita environmental impact of cities, including by paying special attention to air quality and municipal and other waste management.

The indicators are:

- 11.6.1 Proportion of urban solid waste regularly collected and with adequate final discharge out of total urban solid waste generated, by cities;

- 11.6.2 Annual mean levels of fine particulate matter (e.g. $P M_{2.5}$ and $P M_{10}$ ) in cities (population weighted).

\subsection{UE goals}

The first European Conference on Sustainable Cities was held in Aalborg in 1994 in which the Aalborg Charter [32] was approved to underline that the "idea of sustainable development helps us to base our standard of living on the carrying capacity of nature... Social justice will necessarily have to be based on economic sustainability and equity, which require environmental sustainability. Environmental sustainability means maintaining the natural capital".

Other conferences were held, where the themes of sustainable development were reiterated, for example, in Lisbon in 1996, Hannover in 2000, and Aalborg in 2004.

The main document of planning and programming in which the themes of sustainable development and city logistics have been considered at European level are:

- Action Plan on urban mobility [33];

- The Europe 2020 strategy [34];

- Transport White Paper [35] and the following guidelines on Sustainable Urban Mobility Plan [36];

- European action for sustainability [37];

- Country Report Italy 2019 [38].

In 2009 the European Commission adopted the Action Plan on urban mobility proposing "twenty measures to encourage and help local, regional and national authorities in achieving their goals for sustainable urban mobility. With the Action Plan, the European Commission presented for the first time a comprehensive support package in the field of urban mobility" [33].

In 2010 the EU launched The Europe 2020 strategy, the agenda for growth and jobs for the current decade. It is used as a reference framework for activities at EU and at national and regional levels. EU governments have set national targets to help achieve the overall EU targets [34], in which it needs recall:

- Climate change and energy: greenhouse gas emissions 20\% lower than 1990 levels $-20 \%$ of energy coming from renewables $-20 \%$ increase in energy efficiency.

In 2011 the Transport White Paper "Roadmap to a Single European Transport Area: Towards a Competitive and Resource Efficient Transport System" advised cities to develop 
Sustainable Urban Mobility Plans [35]. The European Commission adopted a roadmap of 40 concrete initiatives for the next decade to build a competitive transport system to increase mobility, remove major barriers in key areas and fuel growth and employment.

By 2050, key goals will include:

- no more conventionally-fuelled cars in cities;

- $40 \%$ use of sustainable low carbon fuels in aviation; at least $40 \%$ cut in shipping emissions.

In 2013, the European Commission developed the Guidelines on Sustainable Urban Mobility Plans [36].

In 2016, the European Commission outlined its strategic approach to implementing the 2030 Agenda, including the objectives of sustainable development [36].

The document related to this communication, European action for sustainability, presents a comprehensive overview of the contribution of European policies and initiatives to achieving sustainable development goals, within the EU and through its external action, and summarizes the most important actions that The European Union is launching for each of the 17 sustainable development goals.

To go from plan to realization, EU finances different program; one of the most important program is the Regional Operational Programme 2014-2020 (POR) managed by DG Regio. In the same way and with the same objectives Italian State finances the Action and Cohesion Programme 2014-2020 (PAC).

In 2019 the European Commission has drafted a working document, Country Report Italy 2019 , in which environmental sustainability is placed as one of the pillars of programming [38] for next POR 2021-2027. The climate sector is one of the "Specific challenges of the report; in relation to the achievement of the ambitious 2030 EU energy and climate targets calls for sustained green investments, while Italy is currently on track to achieve the 2020 binding targets on greenhouse gas emissions and renewable (with a $20 \%$ decrease of emissions, with respect to a target of $11 \%$ for 2017), progress has been stagnating in the last few years. ... There is a need to integrate climate change mitigation and adaptation policies across all sectors, including transport."

In the Annex D: "Investment guidance on cohesion policy funding 2021-2027 for Italy" five objectives are fixed; the "Policy Objective 2: A low carbon and greener Europe - Clean and fair energy transition, green and blue investment, circular economy, climate adaptation and risk prevention".

The objective 2 is directly related to the environmental sustainability; it focuses on:

- energy efficiency and renewable energies;

- adaptation to climate change, risk prevention, catastrophe resilience;

- sustainable water and waste management and the circular economy.

\subsection{Italian goals}

At national level, the Italian Ministry of Environment developed a National Plan for Sustainable Development [39], in 1993, for the implementation of Agenda 21. The Plan provides actions in the productive sectors such as industry, agriculture and tourism, in basic infrastructures (energy and transport) and in the waste sector. This is the first Italian document on the environment that constitutes a reference for the legislature and for the program of the government. 
With the 2030 Agenda, in 2017, Italy was carried out a first attempt to verify the distance of our country from the targets set by the Agenda. The Strategia Nazionale per lo Sviluppo Sostenibile (SNSvS) was drafted by the national government to identify the opportunities and challenges or which to provide an answer [40].

The SNSvS is structured in five areas, corresponding to the so-called " $5 \mathrm{P}$ " of sustainable development proposed by the 2030 Agenda: People, Planet, Prosperity, Peace and Partnership. A sixth area is dedicated to the so-called sustainability vectors, to be considered as essential elements for the achievement of national strategic objectives.

Each area contains Strategic Choices and Strategic Objectives for Italy, related to the 2030 Agenda. The partnership area, in particular, incorporates the contents of the "Three-Year Planning and Guidance Document for International Development Cooperation".

The strategic choices identify the priorities to which Italy is called to respond. They reflect the transversal nature of the 2030 Agenda, integrating the three dimensions of sustainability: environment, society and economy. Each choice is associated with a preliminary selection of national level implementation tools.

The document also provides a first set of monitoring indicators related to the goals to achieve.

The topic of climate has been deepened in the SNSvS. In relation to the prosperity area, the choice "IV. Decarbonize the economy", gives objectives as:

- IV.2 Increasing sustainable mobility of people and goods;

- IV.3 Breaking down greenhouse gas emissions in non-ETS sectors.

To increase sustainable mobility of people and goods, it's necessary to

- 7.3 Double the overall rate of energy efficiency improvement by 2030.

An area is dedicated to sustainability vectors that are cross-cutting areas of action of the SNSvS, to be considered as fundamental levers to start, guide, manage and monitor the integration of sustainability in policies, plans and projects, in line with the transformative process triggered at the international level by the 2030 Agenda.

About the indicators, they are detailed according to the goal. As regards the goal "sustainable cities and communities" there are 13 indicators. The following can be related to city logistics:

- Exposure of the urban population to particulate air pollution $<2.5 \mu \mathrm{m}$;

- Exposure of the urban population to particulate air pollution $<10 \mu \mathrm{m}$;

- Exceedances of the daily limit value envisaged for PM10 in the provincial capital municipalities.

\subsection{Calabria goals}

Calabria Region is developing specific activities in line with the UN, the EU and the Italian State for sustainable development.

Sustainability is a central theme for the Economy and Finance Document of Calabria Region 2019-2021 (EFD) [41] which stated that for the development of the Calabrian production system it is necessary to pursue the following goals: competitiveness and innovation; internationalization and attraction; material and immaterial accessibility and development sustainability.

Sustainability is again a central theme for the Regional Transportation Plan published in 2016 [42]. In the Plan Calabria promotes the pursuing of main goals: regional economic 
development, external and internal accessibility, in a general framework of sustainability. The objective 9 specifically regards "Sustainability and streamlining".

The Sustainable Building Program has been launched by the Calabria Region introducing the obligation of environmental sustainability certification for all public buildings or financed with public funds. It has given a strong acceleration in the process of evolution of the Calabrian construction sector towards greater sustainability and placing Calabria in a position to become a good practice at national level, among the first in Italy.

The Calabria Region has already started the first steps towards the SRSvS that will involve, in a transversal way all the five areas (5P) proposed by the Agenda 2030: People, Planet, Prosperity, Peace and Partnership. This has started with the stipulation of a specific agreement with the Ministry of the Environment and the Protection of the Territory and the Sea (MATTM), with which the Region has undertaken to carry out this strategic path that will involve not only the joints of the Executive regional, but also the Calabrian institutions and all the stakeholders that will be able to give a proactive contribution to the strategy.

\section{SUSTAINABLE DEVELOPMENT REALIZATION: THE CITY LOGISTICS EXAMPLE}

The Calabria region has launched initiatives in its own territory concerning city logistics. These activities have been developed in three phases:

- planning;

- programming;

- execution.

Planning was carried out thanks to the Regional Transportation Plan (RTP), adopted, in its final proposal, with DGR n. 503 of 06/12/2016, approved with DCR 157 of 19/12/2016 and positively evaluated by the EU Commission, Directorate General for Regional and Urban Policy as communicated with note $n .1086324$ of 01/03/2017 [42].

The RTP outlines the framework to support the choices of Calabria region, in terms of transport and logistics, in the medium and long term.

The RTP is in line with the international and national objectives of sustainability, in fact the general vision envisages the achievement of a Mobility System for Calabria that allows regional economic development, external and internal accessibility, in a general framework of sustainability.

The RTP is divided into four chapters and ten appendices. Chapter 4 defines ten strategic objectives for the pursuing of the general vision; each objective corresponds to a strategic action, in turn declined in ten operational measures.

In the Objective 2 "Urban areas", Action 2 "Measures for infrastructure upgrading and services in urban areas" there is a specific measure related to city logistics (2.5):

Measures for city logistics:

- supply regulation

- regulation of access times,

- regulation of accesses in relation to the dimensions of freight vehicles,

- regulation of preferential lanes use for local public transport,

- regulation of accesses of the most central areas with the established of an NDA system (nearby delivery area),

- integration with long-distance intermodal transport for the collection/distribution of urban goods, with the possible preparation of the UDC (Urban Distribution Centre); 
- demand management

- support to urban policies aimed at promoting innovative models based on cooperation among the actors involved, and the development of local public and private partnerships among the various actors,

- rationalization of distribution, with the maximization of loads per vehicle and the minimization of total vehicles;

- infrastructural interventions

- $\quad$ strengthening of distribution through the lay-bys use (to be booked),

- preparation of UDC and NDA,

- preparation of a Pick-up Point to support the new online purchase models (ecommerce);

- $\quad$ ICT and ITS application

- $\quad$ support to the best practices for the management of goods traffic in urban areas through ITS use;

- use of eco-friendly and innovative vehicles:

- upgrading of zero-impact vehicle fleets,

- regulation of accesses in relation to the environmental performance characteristics of freight vehicles;

- interventions for public-private collaboration;

- analysis and control of all the components of urban logistics with attention to reverse logistics in all segments: from returns to other recovery phases.

The Region is committed to support all the interventions inspired and related to the Action Plan on Urban Mobility (Brussels, COM (2009), 490/5) and in particular to action 19 - Urban Freight Transport, both promoting the dissemination of information both with adequate incentive support for participation in all European tenders, and with specific supplementary contributions for municipalities that win national or supplementary European tenders, considering the priorities obtainable with the interventions envisaged by the POR for efficiency improvement energy.

Note the direct link declared with the EU Action Plan [33] and the SUMP [33] in its objective aims to "reduce air and noise pollution, greenhouse gas emissions and energy consumption".

Programming has started with DGR n. 391 of 10 August 2017; the regional executive council approves the Implementation Program for the City logistics which indicates the programmable measures that can be implemented in line with the Regional Transport Plan. Thanks to the Implementation Program the Calabrian municipalities can receive PAC 20142020 funding to carry out City logistics projects in urban areas with a high population density and trade operators.

Execution has been realized with a call proposed by Calabria Region for giving grants for urban logistics addressed to all the municipalities of Calabria with a population exceeding 30,000 inhabitants and to the Calabrian municipalities with a population of less than 30,000 inhabitants, in which a limited traffic zone (ZTL) is operational.

\section{CONCLUSION}

The urban logistics produced decisive impacts for urban sustainability in environmental, economic and social terms. The freight flows must be re-organized with the objective to reduce negative impacts on the efficiency and effectiveness of supply chains, in this way the goal of sustainability can be pursuit. 
The paper has addressed the issue of city logistics to clarify how the rules transmission and transposition from one level to another occurs. Fig. 4 shows a framework that schematizes the rules process at different territorial administrative levels. The absence of a well-defined link between one level and another is evidently and only a strong choice of the Executive of each level gives the possibility to pursuit the sustainable goal.

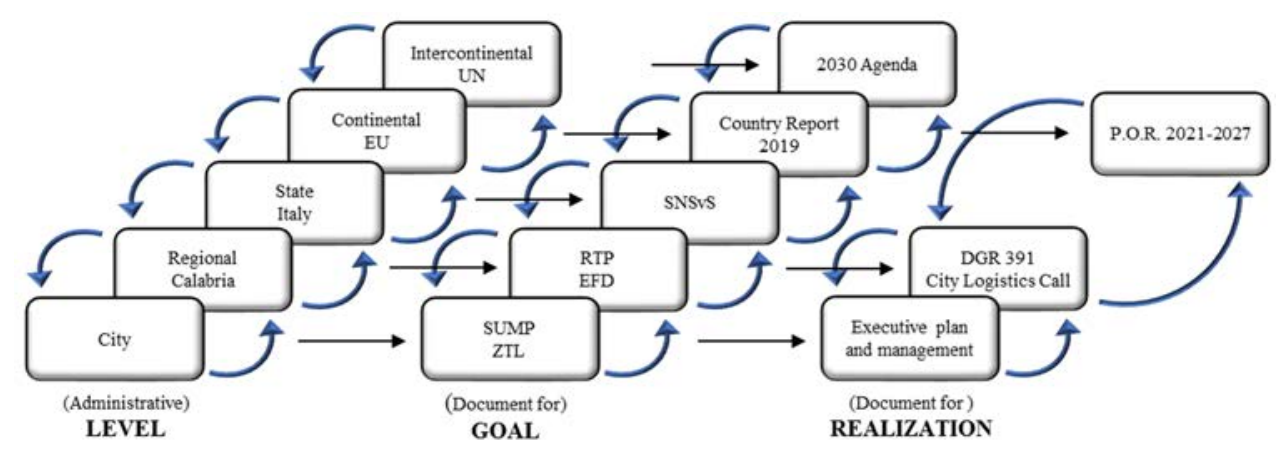

Figure 4: Rules processes at different level.

Finally, the case of Calabria is reported. To pursue intercontinental goals, through planning tools, such as the RPT and the EFD, has finalized a call becoming an exemplary case of best practices. Can be noted that at higher level, as Italy and EU, the problem can be evaluated and addressed because it is easy to finance by means of EU POR or of National PAC specific strategy for city logistics in the SUMP context.

\section{REFERENCES}

[1] Ducret, R., Parcel deliveries and urban logistics: Changes and challenges in the courier express and parcel sector in Europe - The French case. Research in Transportation Business Management, 11, pp. 15-22, 2014.

[2] Visser, J., Nemoto, T. \& Browne, M., Home delivery and the impacts on urban freight transport: A review. Eighth International Conference on City Logistics, 125, pp. 1527, 2014.

[3] Baur, A.H., Thess, M., Kleinschmit, B. \& Creutzig, F., Urban climate change mitigation in Europe: Looking at and beyond the role of population density. Journal of Urban Planning and Development, 140(1), 2014.

[4] Russo, F. \& Comi, A., Investigating the effects of city logistics measures for city economy. Proceedings of City Logistics Conference XI, Dubrovnik, Croatia, 2019.

[5] Russo, F. \& Comi, A., From city logistics theories to city logistics planning. City Logistics 3: Towards Sustainability and Liveable Cities, eds E. Taniguchi \& R.G. Thompson, ISTE, John Wiley: London, pp. 329-348, 2018.

[6] Waygood, E.O.D., Chatterton, T. \& Avineri, E., Comparing and presenting city-level transportation $\mathrm{CO}_{2}$ emissions using GIS. Transportation Research Part D, 24, pp. 127-134, 2013.

[7] Taniguchi, E., City logistics for sustainable and liveable cities. Green Logistics and Transportation: A Sustainable Supply Chain Perspective, eds B. Fahimia, M.G.H. Bell, D.A. Hensher \& J. Sarkis, Springer: Cham, Switzerland, pp. 49-60, 2015. 
[8] Russo, F. \& Comi, A., Urban freight transport planning towards green goals: Synthetic environmental evidence from tested results. Sustainability 2016, 8(4), p. 381, 2016. DOI: $10.3390 / \mathrm{su} 8040381$.

[9] Taniguchi, E., Fwa, T.F. \& Thompson, R.G., Urban Transportation and Logistics: Health, Safety, and Security Concerns, CRC Press: Boca Raton, 2013.

[10] Musolino, G., Polimeni, A., Rindone, C. \& Vitetta A., Planning urban distribution center location with variable restocking demand scenarios: General methodology and testing in a medium-size town. Transport Policy, 80, pp. 157-166, 2019.

[11] Musolino, G., Vitetta, A. \& Polimeni, A., Freight vehicle routing with reliable link travel times: A method based on network fundamental diagram. Transportation Letters: The International Journal of Transportation Research, 10(3), pp. 159-171, 2018.

[12] Gattuso, D. \& Pellicanò, D.S., Advanced methodological researches concerning ITS in freight transport. Procedia - Social and Behavioral Sciences, 111, pp. 994-1003, 2014.

[13] Gattuso, D., Cassone, G.C. \& Pellicanò, D.S., A micro-simulation model for performance evaluation of a logistic platform. Transportation Research Procedia, $\mathbf{3}$, pp. 574-583, 2014.

[14] Elvik, R., Vaa, T., Erke, A. \& Sorensen, M., The Handbook of Road Safety Measures, Emerald Group Publishing: Bingley, 2009.

[15] Russo, F. \& Comi, A., From the analysis of European accident data to safety assessment for planning: The role of goods vehicles in urban areas. European Transport Research Review, 9(9), pp. 1-12, 2017.

[16] Stathopoulos, A., Valeri, E. \& Marcucci, E., Stakeholder reactions to urban freight policy innovation. Journal of Transport Geography 22, pp. 34-45, 2012.

[17] Russo, F., Panuccio, P. \& Rindone, C., European plans for smart city: From theories and rules to logistics test case. European Planning Studies, 2016.

DOI: 10.1080/09654313.2016.1182120.

[18] Faludi, A., Planning Theory, Pergamon Press: Oxford, 1973.

[19] Taylor, N., Urban Planning Theory since 1945, SAGE: London, 1998.

[20] Hall, P.G., Urban and Regional Planning, 4th ed., Routledge: London, 2002.

[21] Vitetta, A., A quantum utility model for route choice in transport systems. Travel Behaviour and Society, 3, pp. 29-37, 2016.

[22] Russo, F. \& Musolino, G., A unifying modelling framework to simulate the spatial economic transport interaction process at urban and national scales. Journal of Transport Geography, 24, pp. 189-197, 2012.

[23] Healey, P. \& Williams, R., European urban planning systems: Diversity and convergence. Urban Studies, 30(4/5), pp. 701-720, 1993.

[24] Cirianni, F., Panuccio, P. \& Rindone, C., A comparison of urban planning systems between the UK and Italy: Commercial development and city logistic plan. WIT Transactions On The Built Environment, vol. 130, WIT Press: Southampton and Boston, pp. 785-796, 2013.

[25] World Commission on Environment and Development (WCED), Report of the World Commission on Environment and Development: Our Common Future, 1987. https://sustainabledevelopment.un.org/content/documents/5987our-commonfuture.pdf.

[26] International Union for Conservation of Nature (IUCN), World Conservation Strategy. Living Resources Conservation for Sustainable Development, 1980.

https://portals.iucn.org/library/efiles/documents/wcs-004.pdf. 
[27] United Nations, Agenda 21: United Nations Conference on Environment and Development, 1992.

https://sustainabledevelopment.un.org/content/documents/Agenda21.pdf.

[28] United Nations, United Nations Framework Convention on Climate Change, 1992. https://unfccc.int/resource/docs/convkp/conveng.pdf.

[29] United Nations, Kyoto Protocol: Reference Manual, 1992. https://unfccc.int/resource/docs/publications/08_unfccc_kp_ref_manual.pdf.

[30] United Nations, Transforming our World: The 2030 Agenda for Sustainable Development, 2015.

https://sustainabledevelopment.un.org/content/documents/21252030\%20Agenda\%20 for\%20Sustainable\%20Development $\% 20$ web.pdf.

[31] United Nations, Global Indicator Framework for the Sustainable Development Goals and Targets of the 2030 Agenda for Sustainable Development, 2018.

https://unstats.un.org/sdgs/indicators/Global\%20Indicator\%20Framework\%20after\% 20refinement_Eng.pdf.

[32] European Conference on Sustainable Cities and Towns, Charter of European Cities and Towns Towards Sustainability, 1994.

http://portal.uur.cz/pdf/aalborg-charter-1994.pdf.

[33] European Commission, Action Plan on urban mobility, 2009.

https://ec.europa.eu/transport/themes/urban/urban_mobility/action_plan_en.

[34] European Commission, Communication from the Commission: Europe 2020. A strategy for smart, sustainable and inclusive growth, 2010.

https://ec.europa.eu/info/business-economy-euro/economic-and-fiscal-policycoordination/eu-economic-governance-monitoring-prevention-correction/europeansemester/framework/europe-2020-strategy_en.

[35] European Commission, White Paper 2011. Roadmap to a Single European Transport Area: Towards a Competitive and Resource Efficient Transport System, 2011.

https://ec.europa.eu/transport/themes/strategies/2011_white_paper_en.

[36] European Commission, Guidelines: Developing and Implementing a Sustainable Urban Mobility Plan, 2013.

https:/ec.europa.eu/transport/themes/urban/urban_mobility/urban_mobility_actions/ sump_en.

[37] European Commission, Communication from the Commission to the European Parliament, the Council, the European Economic and Social Committee and the Committee of the Regions. Next steps for a sustainable European future European action for sustainability, 2016. https:/ec.europa.eu/europeaid/sites/devco/files/ communication-next-steps-sustainable-europe-20161122_en.pdf.

[38] European Commission, Commission Staff Working Document. Country Report Italy 2019. https://ec.europa.eu/info/sites/info/files/file_import/2019-european-semestercountry-report-italy_en.pdf.

[39] Ministero dell'ambiente, Piano Nazionale per lo Sviluppo Sostenibile in attuazione dell'Agenda 21, 1993.

www.isprambiente.gov.it/files/agenda21/1993-piano-nazionale-per-lo-svilupposostenibile.pdf.

[40] Ministero dell'Ambiente e della Tutela del Territorio e del Mare, Strategia Nazionale per lo Sviluppo Sostenibile, 2017. www.minambiente.it/sites/default/files/archivio_immagini/Galletti/Comunicati/ snsvs_ottobre2017.pdf. 
[41] Regione Calabria, Documento di Economia e Finanza della Regione Calabria (DEFR) per gli anni 2018-2020. Adottato con DCR 277/2017: Nota di aggiornamento del Documento di Economia e Finanza della Regione Calabria (DEFR) per gli anni 20182020 (Paragrafo 6 del principio applicato della contabilità - allegato 4.1 e art. 36 del decreto legislativo 23 giugno 2011, n. 118), 2017.

[42] Regione Calabria, Piano Regionale dei Trasporti. Adottato con DCR 157/2016: Adozione della proposta di Piano regionale dei trasporti - Piano Direttore e presa d'atto dei relativi documenti previsti dalla procedura di valutazione ambientale strategica/valutazione di incidenza, 2016. 